\title{
Heat increment of feeding and its thermoregulatory benefit in the muskrat (Ondatra zibethicus)
}

\author{
R.A. MacArthur, K.L Campbell \\ Department of Zoology, University of Manitoba, Winnipeg, Manitoba, R3T2N2, Canada
}

Accepted: 12 January 1994

\begin{abstract}
The calorigenic effect of feeding and its potential benefit in defraying thermoregulatory costs and attenuating immersion hypothermia of adult muskrats were investigated. A single session of feeding on aquatic vegetation was sufficient to raise the metabolic rate of muskrats for a period of at least $5 \mathrm{~h}$. The peak postprandial rate of oxygen consumption averaged 1.42 times the level established for fasted animals, and the heat increment of feeding accounted for about $40 \%$ of the metabolizable energy intake of muskrats. There was no evidence of a postprandial rise in oxygen consumption of muskrats that entered water at $18-19^{\circ} \mathrm{C}$ after feeding. In aquatic trials, average and minimum steady-state oxygen consumption rates of fed muskrats were similar to, or even lower than values recorded from fasted animals, implying substitution of heat increment of feeding for thermoregulatory heat production. Our data did not support the hypothesis that heat increment of feeding retards body cooling in water. Net body temperature decline in water was actually higher in fed animals than in fasted controls. However, since previously fed muskrats also entered water at an elevated body temperature, the final body temperature (at 30 min immersion) was similar in all groups. These findings suggest that metabolic heat generated incidental to preimmersion feeding could provide a thermoregulatory benefit to muskrats by reducing the need for active thermogenesis in water.
\end{abstract}

Key words: Heat increment of feeding - Aquatic thermoregulation - Muskrat, Ondatra zibethicus

\section{Introduction}

Despite impressive adaptations for curbing heat loss and responding thermogenically to cold, many aquatic en-

Abbreviations: HIF, heat increment of feeding; MR, metabolic rate; $\mathrm{RMR}$, resting metabolic rate; $T_{\mathrm{b}}$, body temperature; $\mathrm{VO}_{2}$, rate of oxygen consumption

Correspondence to: R.A. MacArthur dotherms reveal only a modest capacity to thermoregulate in water (MacArthur 1989). Faced with the prospect of pending hypothermia, these animals should be expected to capitalize on heat produced incidental to other activities, including swimming and feeding (Costa and Kooyman 1984; Baudinette et al. 1986). They might exploit, for example, the HIF which comprises the additional heat produced in the mechanical processing, digestion, absorption, and metabolic transformations of assimilated nutrients (Blaxter 1989).

That HIF may substitute, at least in part, for coldinduced thermogenesis has been amply demonstrated in a variety of terrestrial endotherms (Simek 1976; Biebach 1984; Masman et al. 1988). The potential for HIF to defray thermoregulatory costs in water was first examined by Costa and Kooyman (1984) in a study of the sea otter, Enhydra lutris. These investigators reported a 54\% rise in peak MR following feeding, and they proposed that these animals rely on HIF for maintaining thermal balance during long rest periods at sea. More recently, Baudinette et al. (1986) showed that the MR of the little penguin, Eudyptula minor, is nearly doubled following feeding, leading these authors to speculate that E. minor also may draw upon HIF to thermoregulate in water.

The possibility that other aquatic endotherms incorporate HIF into thermoregulatory tactics remains to be tested. An excellent model for investigating this problem is provided by the muskrat, Ondatra zibethicus. Holarctic in distribution, these amphibious rodents are surprisingly prone to immersion hypothermia (Hart 1962; MacArthur 1979a, 1984). Even brief episodes of swimming in cold water are sufficient to elicit pronounced abdominal cooling and a threefold rise in MR of $O$. zibethicus (MacArthur 1984). Earlier studies have underscored the value of stored body heat to aquatic endurance in muskrats, and revealed the extent to which these rodents depend upon behavioral mechanism to regulate $T_{\mathrm{b}}$ in nature (MacArthur 1979a, 1984). However, it is conceivable that muskrats might also utilize HIF to attenuate, if not avoid, immersion hypothermia. This is especially 
true in winter, when muskrats feed intermittently throughout the day. During this season, muskrats may average $8-9$ foraging trips per $24-\mathrm{h}$ period, each lasting 20-250 min (MacArthur 1980). It is thus possible that HIF may persist over successive activity bouts in these northern rodents.

The objectives of this study were twofold: first, we wished to estimate the magnitude and approximate duration of HIF in muskrats fed the aquatic vegetation which constitutes their normal diet. To date, almost all studies of HIF in aquatic mammals have dealt with strictly carnivorous species (Gallivan and Ronald 1981; Costa and Kooyman 1984). A second goal was to test the hypothesis that HIF attenuates body cooling and substitutes partially or completely for thermoregulatory heat production in water. This hypothesis predicts that recently fed muskrats should cool less than fasted animals in water, and that differences in MR between fed and fasted animals should be reduced in the aquatic environment. If fed muskrats are more resistant to aquatic cooling, we also predicted that they should engage in more exploratory dives than fasted animals. Since the act of eating involves muscular work which generates substantial heat in at least some mammals (Gallivan and Best 1986; Blaxter 1989), we also determined if feeding in water benefits aquatic thermoregulation in the muskrat.

\section{Materials and methods}

Animals. A total of ten adult muskrats (eight females, two males) ranging in mass from 757 to $1107 \mathrm{~g}$ were used in this study. Muskrats were livetrapped in Oak Hammock marsh near Winnipeg, Manitoba $\left(50^{\circ} 06^{\prime} \mathrm{N} ; 98^{\circ} 20^{\prime} \mathrm{W}\right)$ in early May and transported to the Department of Zoology, University of Manitoba. Animals were maintained on an ad libitum diet of commercial rodent chow (Agway Prolab) supplemented by apples and carrots. Details concerning laboratory holding facilities are provided elsewhere (MacArthur $1979 \mathrm{~b}$; 1984). Muskrats were acclimated to holding conditions for a minimum period of 1 month prior to beginning tests, which were conducted during June and July, 1990 and 1991.

Body temperature measurements. Abdominal $T_{\mathrm{b}}$ was recorded from each animal using a $1.5-\mathrm{g}$ model $\mathrm{X}-\mathrm{M}$ transmitter (mini-Mitters Inc., Sunriver, Ore., USA) surgically implanted into the abdominal cavity. Transmitter calibration and implantation procedures followed MacArthur (1979b) and Dyck and MacArthur (1992). Transmitter signals were detected with a Sony AM receiver. All surgery was completed at least 2 weeks prior to starting experiments.

Heat increment of feeding. The thermogenic response to ingested forage was estimated by monitoring the increase in RMR after a single, $70-\mathrm{min}$ session of feeding. Following a $22-\mathrm{h}$ fast, each muskrat was provided with $270-300 \mathrm{~g}$ (wet mass) of a standardized ration consisting of the stems of sedge (Carex atherodes) and bulrush (Scirpus lacustris), and the stems, roots and rhizomes of cattail (Typha glauca). These emergent species all constitute natural forages of the muskrat in northern prairie marshes. Vegetation was collected from local marshes, including Oak Hammock, usually on the day preceding a given feeding trial.

Prior to feeding, rations were thoroughly washed, blotted dry, and weighed to within $0.1 \mathrm{~g}$. Food was placed in the muskrat's holding cage at 0800 hours and feeding was permitted until 0910 hours, when the animal was removed and immediately installed in the metabolic chamber (see below). An average of 12 min elapsed between the end of feeding and the initiation of metabolic measurements. To estimate dry matter intake in each trial, a duplicate ration sample was prepared, weighed, dried to constant mass at $70^{\circ} \mathrm{C}$, and reweighed. The dry: wet mass ratio derived for this sample was used to calculate dry matter content of the forage ration. This value, less the dry mass of uneaten rations, provided an estimate of dry matter intake.

For each trial, the dried ration sample and uneaten rations were ground separately in a Wiley mill. The gross energy content of each was determined in triplicate using an adiabatic $\mathrm{O}_{2}$ bomb calorimeter (Parr 1241 Calorimeter, Parr Instrument Co., Moline, IIl., USA). On a dry matter basis, the rations fed to muskrats contained, on average, $7.9 \%$ protein, $12.5 \%$ ash, and $61.9 \%$ neutral detergent fiber (feed analysis laboratory, Department of Animal Science, University of Manitoba). The mean ( $\pm \mathrm{SEM}$ ) gross energy content of the forage ration was $16.41 \pm 0.25 \mathrm{~kJ} \cdot \mathrm{g}^{-1}$ dry matter.

All metabolic measurements in air were made at thermoneutrality $\left(15 \pm 0.5^{\circ} \mathrm{C}\right)$. The respirometry chamber consisted of a darkened, 14-1 glass box fitted with a heavy Plexiglas lid and a removable Plexiglas floor. A positive-pressure, open-circuit system similar to that described by MacArthur (1984) was used, in which inlet flow rate was maintained at $4.51 \cdot \mathrm{min}^{-1}$ with a Matheson rotameter calibrated against a model 1057 Brooks Vol-U-Meter. Exhaust gas from the chamber was split into two streams. One stream was routed through drierite followed by soda lime/drierite, and then through a S3-A oxygen analyzer (Applied Electrochemistry Inc.) connected to a two-channel chart recorder (SE-120, BBC Goerz Metrawatt). The second exhaust stream was routed through drierite and then through a CD-3A carbon dioxide analyzer (Applied Electrochemistry Inc.) connected to the second channel of the recorder. Minimum steady-state rates of $\mathrm{O}_{2}$ consumption and $\mathrm{CO}_{2}$ production were calculated for successive 0.5 - $\mathrm{h}$ intervals (Wang and Peter 1975). The respiratory quotient derived from these measurements was used to convert $\mathrm{VO}_{2}$ values to units of heat production, $\mathrm{W} \cdot \mathrm{kg}^{-1}$ (Stanier et al. 1984).

MR was monitored for $7.5 \mathrm{~h}$ following ingestion of the meal. Control runs of similar duration were also performed on each ani$\mathrm{mal}$ in a fasted state, following $22 \mathrm{~h}$ food deprivation. Only one feeding and one control trial were performed per animal, with the order of the trials randomized. Since adequate resting values were not obtained for two of the muskrats tested, data for these individuals were omitted from the analyses.

Aquatic trials. Aquatic tests were performed in a fibreglass-lined, plywood tank $(183 \times 175 \times 72 \mathrm{~cm})$ housed in a controlled-environment room. The tank was filled to a depth of $68 \mathrm{~cm}$ with water at $18.5 \pm 0.5^{\circ} \mathrm{C}$. Wire screen covers secured to a frame $3 \mathrm{~cm}$ below water level prevented diving muskrats from surfacing at any point in the tank other than the metabolic chamber. The latter consisted of a 20.5-1 Plexiglas box fastened to the submerged frame (MacArthur and Krause 1989). Exhaust gas from the chamber was drawn by vacuum through drierite and soda lime/drierite trains and then through a calibrated Matheson rotameter at a rate of $10.51 \cdot \mathrm{min}^{-1}$. Otherwise, the respiratory set-up and the method for calculating average $\dot{V} \mathrm{O}_{2}$ in water were identical to those described by MacArthur and Krause (1989). When possible, minimum steady-state $\dot{\mathrm{VO}}{ }_{2}$ in water was also calculated, using Eq. 4a of Withers (1977). In these instances, muskrats typically floated quietly in the chamber and only occasionally engaged in short exploratory dives. Abdominal $T_{\mathbf{b}}$ was recorded at 5 -min intervals throughout each $30 \mathrm{~min}$ immersion period. The frequency and duration of all voluntary dives were also noted.

Muskrats were tested under four experimental situations. Trial A provided a control in which muskrats were fasted for $22 \mathrm{~h}$ and received no food either before or during immersion. In Trial $\mathbf{B}$, fasted muskrats were provided with a natural forage ration identical to that described for the HIF experiment (see above). In this case, animals were permitted to feed for $70 \mathrm{~min}$ prior to entering water, but not during immersion. Trial $\mathrm{C}$ involved muskrats that 
were not fasted, but were maintained on the standard laboratory diet of rodent chow supplemented by apples and carrots. To ensure that they had recently fed, animals in this trial were provided additional apples and carrots $70 \mathrm{~min}$ before release into the tank. Trial $D$ involved fasted muskrats that were fed only in the water. In this case, the stems and rhizomes of sedge, cattail and bulrush were placed beneath the screen cover of the tank, close to the metabolic chamber. Muskrats could thus "forage" in the tank and consume vegetation they collected while floating in the chamber. Trial D was the only experiment in which muskrats could feed during metabolic measurements. Trial order was randomized and at least $72 \mathrm{~h}$ separated successive tests on the same individual. Each animal was tested twice in a given trial.

Statistical treatment of data. Means were compared with Student's $t$-test or, for multiple comparisons, analysis of variance (GLM procedure, Statistical Analysis System, Cary, N.C., USA) and Fisher's LSD test. Significance was set at the 5\% level and means are presented \pm 1 SEM.

\section{Results}

\section{Heat increment of feeding}

The gross energy intake of muskrats fed aquatic emergent vegetation prior to HIF determinations averaged $75.9 \pm 19.3 \mathrm{~kJ}$. This is approximately $12 \%$ of the daily gross energy intake of captive muskrats maintained on similar diets in the laboratory (K.L. Campbell and R.A. MacArthur, unpublished data). Ingestion of the single meal by muskrats was followed by a rise in RMR that persisted throughout the 7.5-h postprandial measurement period (Fig. 1). However, differences in mean $\dot{V} \mathrm{O}_{2}$ between fed and fasted animals were not significant beyond $5 \mathrm{~h}(P>0.05)$, suggesting that the major thermogenic response to feeding was completed within $5 \mathrm{~h}$ of ingesting the meal. The $\dot{V} \mathrm{O}_{2}$ of fasted muskrats did not change significantly during the test session (Fig. 1).

During the first $5 \mathrm{~h}$ following feeding, mean postprandial $\dot{V} \mathrm{O}_{2}\left(0.99 \pm 0.06 \mathrm{ml} \mathrm{O} \mathrm{O}_{2} \cdot \mathrm{g}^{-1} \cdot \mathrm{h}^{-1}\right)$ was 1.24 times the mean postabsorptive value $\left(0.80 \pm 0.02 \mathrm{ml} \mathrm{O}_{2}\right.$. $\left.\mathrm{g}^{-1} \cdot \mathrm{h}^{-1}\right)$. Peak postprandial RMR averaged $1.14 \pm$
$0.07 \mathrm{ml} \mathrm{O} \cdot \mathrm{g}^{-1} \cdot \mathrm{h}^{-1}$ or 1.42 times the control level. Based on the calculated difference in heat production of fed and fasted muskrats (Fig. 1), the estimated HIF was $16.9 \mathrm{~kJ}$. Assuming an apparent metabolizable energy coefficient of 0.531 (K.L. Campbell and R.A. MacArthur, unpublished data), this heat increment would account for $42 \%$ of the metabolizable energy $(40.3 \mathrm{~kJ})$ ingested by muskrats.

For the first $30 \mathrm{~min}$ of testing, the mean $T_{\mathrm{b}}$ of postprandial muskrats $\left(38.0 \pm 0.09^{\circ} \mathrm{C}\right)$ exceeded that of controls $\left(37.2 \pm 0.29^{\circ} \mathrm{C} ; t=2.61, d f=14, P<0.03\right)$. Thereafter, $T_{\mathrm{b}}$ was similar in both groups (Fig. $1, P>0.05$ ).

\section{Feeding and aquatic thermoregulation}

Contrary to expectations, net $T_{\mathrm{b}}$ decline in water was greatest in muskrats that had fed prior to immersion (Trials B and C; Table 1, Fig. 2). The initial (preimmersion) $T_{\mathrm{b}}$ of recently fed animals (Trials $\mathrm{B}$ and C) also averaged $1.0-1.2^{\circ} \mathrm{C}$ higher than for animals that were fasted prior to release into the water (Trials $A$ and $D$, Fig. 2). However, owing to the higher cooling rates of postprandial muskrats, mean $T_{\mathrm{b}}$ was similar for all test groups after $30 \mathrm{~min}$ in water (Table $1, P>0.05$ ). Adominal cooling was least pronounced in muskrats that were permitted to feed on aquatic vegetation during the test session (Trial $\mathrm{D}$, Table 1). In all aquatic trials, the net decline in $T_{\mathrm{b}}$ was positively correlated with cumulative dive time (Fig. 3).

There was no evidence of a postprandial rise in $\dot{V} \mathrm{O}_{2}$ of muskrats that entered water after feeding. In fact, the lowest average $\dot{V} \mathrm{O}_{2}$ in water $\left(1.70 \pm 0.06 \mathrm{ml} \mathrm{O}_{2} \cdot \mathrm{g}^{-1}\right.$. $\mathrm{h}^{-1}$ ) was recorded for animals fed prior to immersion (Trial $\mathrm{B}$, Table 1). The highest average $\dot{\mathrm{V}} \mathrm{O}_{2}$ in water $\left(2.24 \pm 0.05 \mathrm{ml} \mathrm{O}_{2} \cdot \mathrm{g}^{-1} \cdot \mathrm{h}^{-1}\right)$ was recorded for Trial D when muskrats could forage underwater and feed in the respirometry chamber. For the remaining trials, minimum steady-state $\dot{V} \mathrm{O}_{2}$ in water was similar $(P>0.05)$, ranging from $1.26 \pm 0.06 \mathrm{ml} \mathrm{O} \cdot \mathrm{g}^{-1} \cdot \mathrm{h}^{-1}$ in Trial $\mathrm{B}$, to $1.35 \pm 0.06 \mathrm{ml} \mathrm{O}_{2} \cdot \mathrm{g}^{-1} \cdot \mathrm{h}^{-1}$ in Trial A.

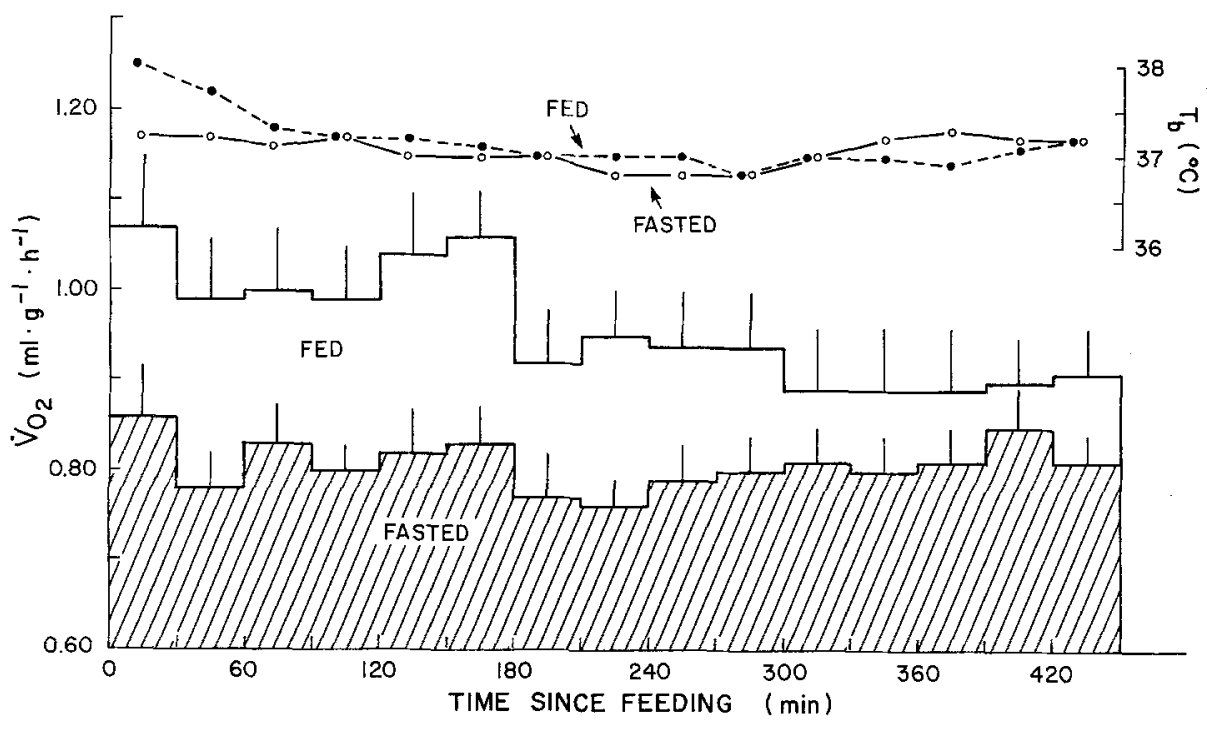

Fig. 1. Mean $\dot{V} \mathrm{O}_{2}$ and telemetered body temperatures $\left(T_{b}\right)$ of muskrats $(n=8)$ after a single session of feeding on aquatic vegetation (open bars, $\bullet$ ), and in postabsorptive state following a 22-h fast (hatched bars, o). Vertical bars denote $1 \mathrm{SEM}$ 


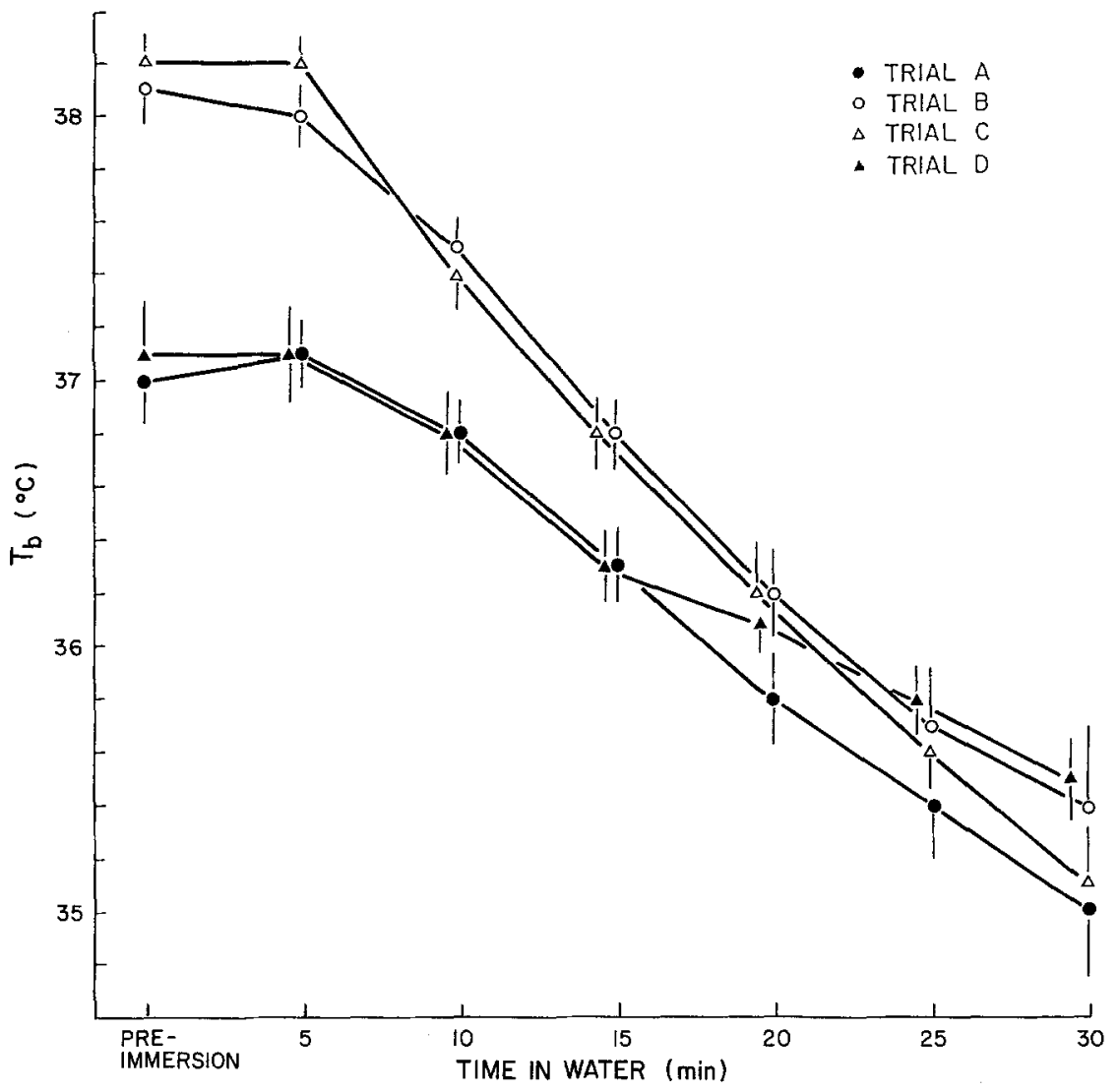

Fig. 2. Temporal variation in mean $\left( \pm\right.$ SEM) body temperature $\left(T_{\mathrm{b}}\right)$ of unrestrained muskrats $(n=10)$ during $30 \mathrm{~min}$ of immersion in water at $18.5 \pm 0.5^{\circ} \mathrm{C}$ (Trials A-D)

Table 1. Summary of diving, average $\dot{V} \mathrm{O}_{2}$, and body temperature responses of unrestrained muskrats $(n=10)$ to $30 \mathrm{~min}$ of immersion in water at $18.5 \pm 0.5^{\circ} \mathrm{C}$

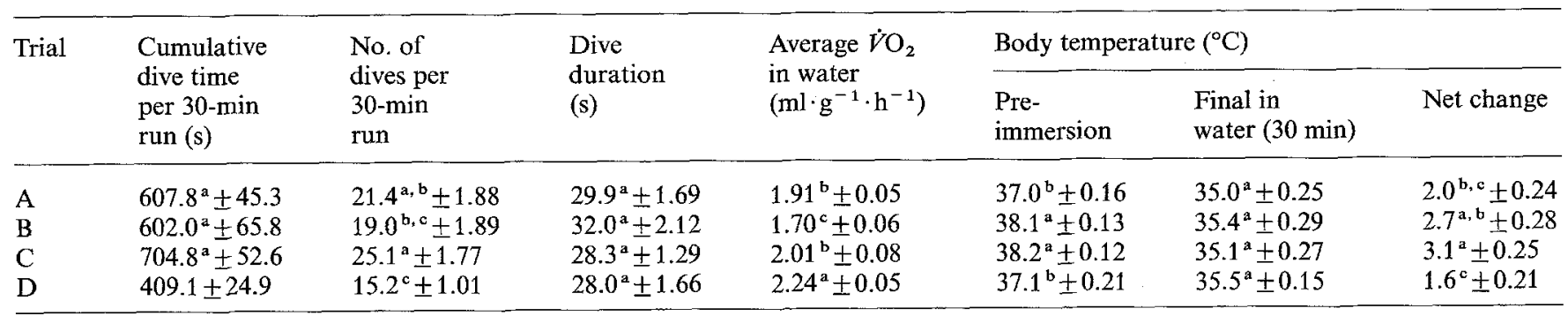

Aquatic tests were performed on animals which were fasted only (Trial A), fed prior to, but not during immersion (Trials B and C), or fasted, but permitted to feed in water during measurements (Trial $\mathrm{D}$; see text for details)

Values are means \pm SEM. Within each column, means sharing the same letter are not significantly different $(P>0.05)$

Cumulative dive time was similar for all trials except D (Table 1). In the latter experiment, animals spent an average of only $22.7 \%(409 \mathrm{~s})$ of each 30 -min session diving, compared to $33.4-39.2 \%(607-705 \mathrm{~s})$ for the remaining trials. The total number of dives per 30-min session was also lowest in Trial D (Table 1). Muskrats in Trial D spent most of each run floating in the respirometry chamber, consuming vegetation retrieved from the tank. The average duration of individual dives was similar for all experiments (Table 1).

\section{Discussion}

Results of this study indicate that a single feeding of emergent vegetation is sufficient to raise the RMR of muskrats for a period of at least $5 \mathrm{~h}$. Since muskrats in winter feed intermittently throughout the day, often leaving their dens for periods exceeding $1 \mathrm{~h}$ (MacArthur 1980 ), the HIF response is of adequate duration to be of thermoregulatory benefit to foraging animals. Conceivably, HIF generated in a given feeding session could defray thermoregulatory costs during the same, as well as on subsequent foraging trips during this season.

At low temperatures, a diminution in the thermogenic response to feeding is usually assumed to indicate partial substitution of HIF for thermoregulatory metabolic costs (Simek 1976; Masman et al. 1988; Klaussen et al. 1989; Robbins 1993). If this assumption applies also to muskrats in water, then our results strongly suggest that HIF offsets energy expended for aquatic thermoregulation. In no case did we detect a postprandial rise in 


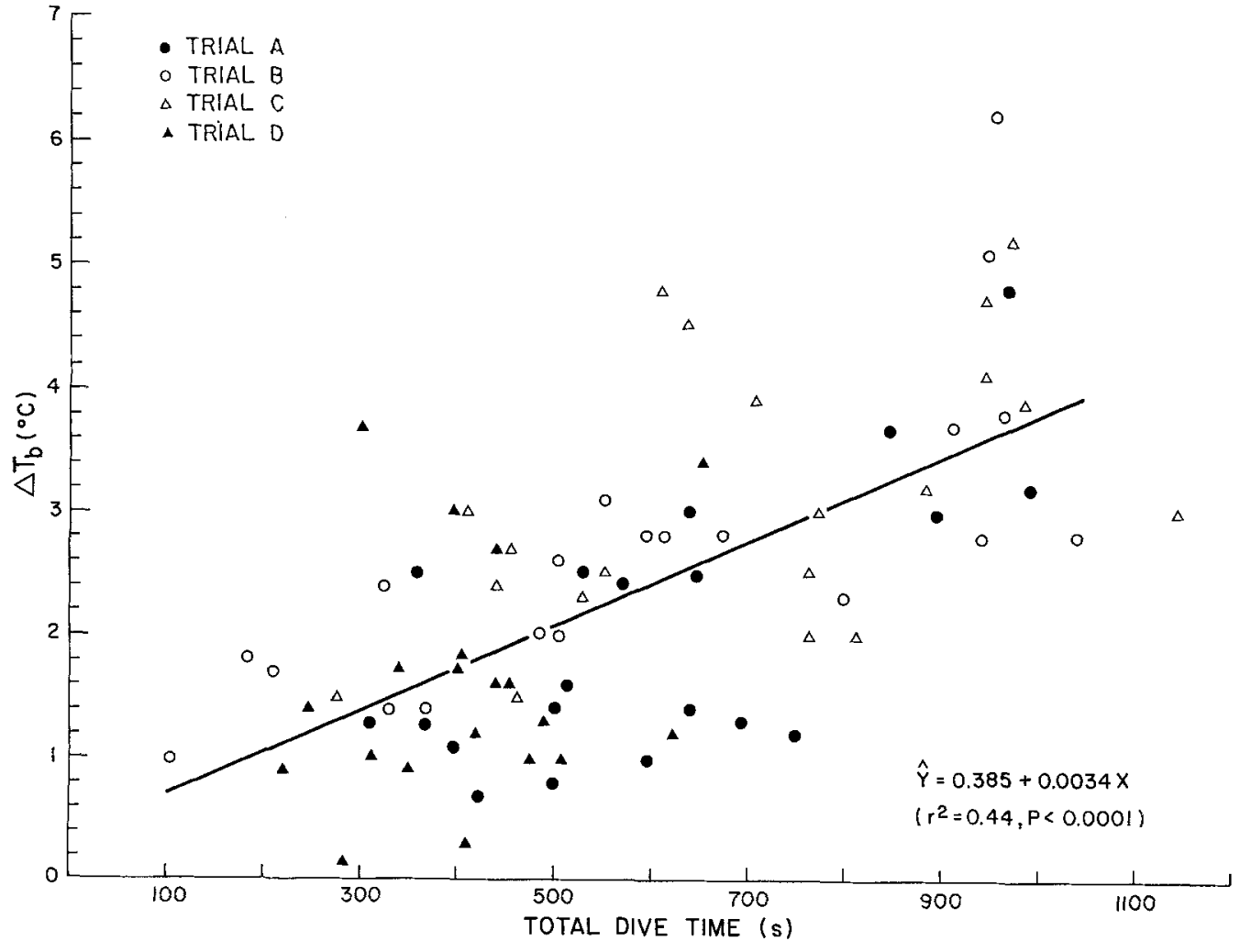

Fig. 3. The relationship between net body temperature change $\left(\Delta T_{\mathrm{b}}\right)$ and cumulative dive time of unrestrained muskrats $(n=10)$ immersed for $30 \mathrm{~min}$ in water at $18.5 \pm 0.5^{\circ} \mathrm{C}$ (Trials A-D). $\Delta T_{\mathrm{b}}=$ final $T_{\mathrm{b}}$ in water-preimmersion $T_{\mathrm{b}}$ the $\dot{V} \mathrm{O}_{2}$ of immersed animals. The $\dot{V} \mathrm{O}_{2}$ of muskrats permitted to feed immediately prior to entry into water (Trial B) was actually less than that of fasted controls (Trial A) despite similar dive times (Table 1).

Implicit in the argument that HIF substitutes for cold thermogenesis is the assumption that digestion and nutrient assimilation persist in the cold-challenged animal. In the case of a semiaquatic mammal like the muskrat, this tenet may be invalid if the animal vasoconstricts abdominal tissues in water, thereby suspending nutrient digestion and absorption. Thus, the apparent absence of a postprandial rise in $\dot{V} \mathrm{O}_{2}$ of immersed muskrats might also indicate a temporary arrest in gut and liver functions associated with immersion. Further research involving regional blood flow measurements of muskrats in water is clearly needed to resolve this issue.

Interestingly, the only trial in which feeding appeared to influence the $\dot{V} \mathrm{O}_{2}$ of immersed muskrats was Trial $\mathrm{D}$, in which animals were permitted to feed while floating in the respirometry chamber. The $17 \%$ increase in $\dot{V} \mathrm{O}_{2}$ of these animals is attributed to the muscular work required in the handling, mastication, and ingestion of aquatic plants. It is noteworthy that the $\dot{V} \mathrm{O}_{2}$ of animals in Trial $\mathrm{D}$ increased relative to controls, despite a reduction in cumulative dive time (Table 1).

We found no evidence that HIF retards body cooling in water. In fact, net $T_{\mathrm{b}}$ decline was higher in fed animals than in fasted controls, implying a greater loss of body heat to the surrounding medium following ingestion of food. However, because previously fed muskrats also entered water at an elevated $T_{\mathrm{b}}$, the final $T_{\mathrm{b}}$ (at $30 \mathrm{~min}$ immersion) was similar for all groups (Table 1). Thus, one potential thermoregulatory benefit of preimmersion feeding in muskrats may be the incidental storage of metabolic heat that could reduce the need for active thermogenesis in water.

This heat storage benefit might explain, for example, why mean $\dot{V}_{2}$ was $11 \%$ lower for fed muskrats in Trial B than for fasted animals in Trial A (Table 1). Although fed muskrats in Trial $\mathrm{C}$ did not demonstrate a reduction in $M R$, animals in this group also tended to do more diving than controls (Table 1). Consequently, increased motor costs associated with underwater swimming (MacArthur and Krause 1989) could have masked any thermoregulatory saving accrued from preimmersion heat storage in Trial $\mathrm{C}$ animals. Based on HIF trials (Fig. 1), the postprandial rise in $T_{\mathrm{b}}$ associated with a single session of feeding appears to be relatively shortlived, since it did not persist beyond about $30 \mathrm{~min}$.

The only case in which we found evidence of attenuated body cooling in water was Trial D. While muscular heat generated secondarily to feeding might have contributed to the reduced $T_{\mathrm{b}}$ drop of muskrats in Trial D, a more important factor was probably the reduction in cumulative dive time of these animals (Table 1). As revealed in Fig. 3, net $T_{\mathrm{b}}$ decline increases with cumulative dive time in muskrats, an observation we attribute to the enhanced convective heat loss associated with wholebody submersion (MacArthur 1984).

The results of our HIF trials concur with earlier studies indicating that the calorigenic effect of feeding often accounts for more than $30 \%$ of metabolizable energy in mammalian herbivores (Robbins 1993). In the case of $O$. zibethicus, this observation may in part reflect the 
high fiber content of the animal's diet (Robbins 1993). To our knowledge, the only other study of HIF in a herbivorous aquatic mammal is an investigation of the Amazonian manatee, Trichechus inunguis by Gallivan and Best (1986). These investigators were unable to detect any postprandial rise in the $\dot{V} \mathrm{O}_{2}$ of manatees following a single feeding of aquatic vegetation. Not surprisingly, the peak postprandial rise in $\dot{V O}_{2}$ of muskrats $(42 \%)$ was less than the $54-100 \%$ increase previously reported for marine birds and mammals fed high-protein, animal tissue diets (Gallivan and Ronald 1981; Costa and Kooyman 1984; Baudinette et al. 1986).

Finally, Wilson and Culik (1991) have proposed that a considerable portion of the HIF response may, in fact, represent heat required to warm ingested food from ambient to core temperature. In our HIF trials, muskrats consumed an average of $61.3 \mathrm{~g}$ (wet mass) of aquatic vegetation with a mean water content of $90.2 \%$ and an initial temperature close to $14^{\circ} \mathrm{C}$. If it is assumed this vegetation had a specific heat equivalent to that of water $\left(4.187 \mathrm{~kJ} \cdot \mathrm{kg}^{-1} \cdot{ }^{\circ} \mathrm{C}^{-1}\right)$, then only $5.9 \mathrm{~kJ}$, or about $35 \%$ of HIF would be utilized to warm ingested food to core $T_{\mathrm{b}}$. This calculation likely over-estimates the true contribution of HIF to warming food, since feeding in this study was initiated more than $1 \mathrm{~h}$ prior to starting metabolic measurements. However, the cost of warming ingested food in nature may be significant, especially during winter, when muskrats consume large quantities of submerged vegetation retrieved from nearfreezing water. As Wilson and Culik (1991) point out, the metabolic costs of warming ingested food could be mitigated in species like the muskrat, by spreading the foraging effort over a longer period of the day. This aspect of the muskrat's winter ecology and foraging energetics clearly warrants further investigation.

Acknowledgements. We would like to thank D. Jeske for technical assistance and W. Heck for preparing illustrations. The cooperation provided by the Manitoba Department of Natural Resources, Wildlife Branch, is gratefully acknowledged. This research was supported by an operating grant to R.A.M. and a postgraduate scholarship to K.L.C. from the Natural Sciences and Engineering Research Council of Canada.

\section{References}

Baudinette RV, Gill P, O'Driscoll M (1986) Energetics of the little penguin, Eudyptula minor: temperature regulation, the calorigenic effect of food, and moulting. Aust J Zool 34:35-45

Biebach H (1984) Effect of clutch size and time of day on the energy expenditure of incubating starlings (Sturnus vulgaris). Physiol Zool 57:26-31

Blaxter K (1989) Energy metabolism in animals and man. Cambridge University Press, Cambridge
Costa DP, Kooyman GL (1984) Contribution of specific dynamic action to heat balance and thermoregulation in the sea otter Enhydra lutris. Physiol Zool 57:199-203

Dyck AP, MacArthur RA (1992) Seasonal patterns of body temperature and activity in free-ranging beaver (Castor canadensis). Can J Zool 70:1668-1672

Gallivan GJ, Ronald K (1981) Apparent specific dynamic action in the harp seal (Phoca groenlandica). Comp Biochem Physiol 69 A: $579-581$

Gallivan GJ, Best RC (1986) The influence of feeding and fasting on the metabolic rate and ventilation of the Amazonian manatee (Trichechus inunguis). Physiol Zool 59:552-557

Hart JS (1962) Mammalian cold acclimation. In: Hannon JP, Viereck E (eds) Comparative physiology of temperature regulation, vol 2. Arctic Aeromedical Laboratory, Fort Wainwright, Alaska, pp 203-228

Klaussen M, Bech C, Slagsvold G (1989) Basal metabolic rate and thermal conductance in arctic tern chicks and the effect of heat increment of feeding on thermoregulatory expenses. Ardea 77:193-200

MacArthur RA (1979a) Seasonal patterns of body temperature and activity in free-ranging muskrats (Ondatra zibethicus). Can J Zool 57:25-33

MacArthur RA (1979b) Dynamics of body cooling in acclimatized muskrats (Ondatra zibethicus). J Therm Biol 4:273-276

MacArthur RA (1980) Daily and seasonal activity patterns of the muskrat Ondatra zibethicus as revealed by radiotelemetry. Holarct Ecol 3:1-9

MacArthur RA (1984) Aquatic thermoregulation in the muskrat (Ondatra zibethicus): energy demands of swimming and diving. Can J Zool 62:241-248

MacArthur RA (1989) Aquatic mammals in cold. In: Wang LCH (ed) Advances in comparative and environmental physiology, vol 4. Animal adaptation to cold. Springer, New York, pp 289325

MacArthur RA, Krause RE (1989) Energy requirements of freely diving muskrats (Ondatra zibethicus). Can J Zool 67:2194-2200

Masman D, Daan S, Dietz M (1988) Heat increment of feeding in the kestrel, Falco tinnunculus, and its natural seasonal variation. In: Bech C, Reinertsen RE (eds) Physiology of cold adaptation in birds. Plenum Press, New York, pp 123-135

Robbins CT (1993) Wildlife feeding and nutrition, 2nd edn. Academic Press, San Diego

Simek V (1976) Influence of a single administration of different diets on the energy metabolism at temperature of 10,20 and $30{ }^{\circ} \mathrm{C}$ in the golden hamster. Physiol Bohemoslov 25:251-253

Stanier MW, Mount LE, Bligh J (1984) Energy balance and temperature regulation. Cambridge University Press, Cambridge, UK

Wang LCH, Peter RE (1975) Metabolic and respiratory responses during Helox-induced hypothermia in the white rat. Am J Physiol 229:890-895

Wilson RP, Culik BM (1991) The cost of a hot meal: facultative specific dynamic action may ensure temperature homeostasis in post-ingestive endotherms. Comp Biochem Physiol $100 \mathrm{~A}: 151-154$

Withers PC (1977) Measurements of $\dot{V} \mathrm{O}_{2}, \dot{V} \mathrm{CO}_{2}$, and evaporative water loss with a flow-through mask. J Appl Physiol 42:120123 